\title{
AUTORADIOGRAPHIC STUDY OF THE EFFECTS OF PULSED ELECTROMAGNETIC FIELDS ON BONE AND CARTILAGE GROWTH IN JUVENILE RATS
}

\author{
Janice J. Wilmot, ${ }^{1}$ D. J. Chiego JR, ${ }^{2}$ D. S. Carlson, ${ }^{1}$ C. T. Hanks ${ }^{3}$ and J. J. Moskwa ${ }^{4}$ \\ 'Department of Orthodontics and Pediatric Dentistry, ${ }^{2}$ Department of Cariology and General Dentistry \\ and Biological and Materials Sciences, ${ }^{3}$ Department of Oral Medicine, Pathology and Surgery and \\ ${ }^{4}$ Department of Internal Medicine-Nuclear Medicine, The University of Michigan, Schools of Dentistry \\ and Medicine, Ann Arbor, MI 48109, U.S.A.
}

(Accepted 14 August 1992)

\begin{abstract}
Summary-Application of pulsed electromagnetic fields (PEMF) has been used in growth and repair of non-union bone fractures. The similarities between the fibrocartilage callus in non-union bone fractures and the secondary cartilage in the mandibular condyle, both histologically and functionally, lead naturally to study the effects of PEMFs on growth in the condyle. The purposes of this study were: (1) to describe the effects of PEMFs on the growth of the condyle using autoradiography, $\left[{ }^{3} \mathrm{H}\right]$-proline and $\left[{ }^{3} \mathrm{H}\right]$ thymidine, and (2) to differentiate between the effects of the magnetic and electrical components of the field. Male pre-adolescent Sprague-Dawley rats (28 days old) were divided into three experimental groups of five animals each: (1) PEMF-magnetic (M), (2) PEMF-electrical (E) and (3) control, and were examined at three different times-3,7 and 14 days of exposure. Each animal was exposed to the field for 8 h per day. Histological coronal sections were processed for quantitative autoradiography to determine the mitotic activity of the condylar cartilage and the amount of bone deposition. The PEMF (magnetic or electrical) had statistically significant effects only on the thickness of the articular zone, with the thickness in the PEMF-M group being the most reduced. Length of treatment was associated with predictable significant changes in the thickness of the condylar cartilage zones and the amount of bone deposition. As the animals aged, less condylar growth was observed and generally the highest mean thicknesses were found in the 3- and 7-day groups; likewise as more bone was deposited, the 7-day measurements of proline-band thickness were significantly greater than the 3-day measurements. Thus, the PEMF-M had a negative effect on the chondrogenic layer of the articular zone, but no other chondrogenic or osteogenic effects were noted.
\end{abstract}

Key words: pulsed electromagnetic fields, autoradiography, mandible, condylar cartilage.

\section{INTRODUCTION}

Bioelectric interactions and activity are present in many biological tissues and yet are some of the least understood of the physiological processes. Recently, the hypothesis that stimulating bone and cartilage through the application of electric and magnetic fields will affect growth and repair has been proposed and investigated (Bassett, 1968, 1971; Bassett, Pawluk, and Pilla, 1974a; Gupta, Jain, and Tandon, 1991). The main application of PEMFs has been in orthopaedics in healing of non-union bone fractures, with an $80 \%$ success rate for the tibia as reported by Bassett (1982a, b, 1989) and Brighton et al. (1986). The histological features and function of the fibrocartilage callus in non-union bone fractures are similar to those of the secondary cartilage in the mandibular condyle (Gerling, Sinclair and Roa, 1985). Kopman et al. (1987) has noted that molecular changes in proteoglycans in the fracture callus are similar to those seen in normal endochondral ossification.

More recently, research in the area of PEMF stimulation has been directed at understanding the

Abbreviations: ANOVA, analysis of variance; PEMF, pulsed electromagnetic field. mechanisms of response using tissue culture (Norton, 1982; Norton, Hanley and Turkewicz, 1984; Norton, 1985; Norton, Witt and Rovetti, 1988; Iannacone et al., 1988; Aaron, Ciombor and Jolly, 1989). Grodzinsky (1983) conjectured that direct currents do not penetrate the cellular membranes and that control is achieved via extracellular matrix differentiation (Noda and Sato, 1985). Rodan, Bourret and Norton (1978) found that electric fields increased $\left[{ }^{3} \mathrm{H}\right]$ thymidine incorporation into the DNA of chondrocytes, supporting the notion that $\mathrm{Na}$ and $\mathrm{Ca}^{2+}$ fluxes generated by electrical stimulation trigger DNA synthesis. Others have found changes in the second messenger, cAMP, and cytoskeletal rearrangements due to electrical perturbations (Norton, Rodan and Bourret, 1977; Ryaby, Jones and Pilla, 1986; Jones, Pedley and Ryaby, 1986), as well as effects on glycosaminoglycan sulphation, hyaluronic acid, lysozyme activity and polypeptide sequences (Norton, 1982, 1985; Norton et al., 1988; Goodman and Henderson, 1988).

PEMFs, on the other hand, can penetrate cell membranes and either stimulate them or directly affect intracellular organelles (Bawin, Adey and Sabbot, 1978). Aaron et al. (1989) examined the effect of PEMFs on extracellular matrices and in vivo 
endochondral ossification and found increased synthesis of cartilage molecules and maturation of bone trabeculae.

Concurrently, recent research in orthodontics and craniofacial biology has sought a better understanding of craniofacial growth, especially growth of the mandible and condyle, and of orthodontic tooth movement (McNamara, 1972; Petrovic and Stutzmann, 1977; Carlson et al., 1980). The use of perturbations from direct currents for orthodontic tooth movement have been investigated by Davidovitch et al. $(1980 \mathrm{a}, \mathrm{b}, \mathrm{c})$, with results showing increased bone remodelling and concomitant tooth movement. PEMF perturbation was also investigated as part of orthodontic tooth movement by Stark and Sinclair (1987) and in orthopaedic manipulation of mandibular growth by Gerling et al. (1985). They showed, respectively, that there was an increased rate of orthodontic tooth movement on PEMF stimulation and an initial increase in calcification of the hypertrophic layer of the mandibular condylar cartilage; however, this response became attenuated over time.

We have made a quantitative autoradiographic study of the effects of PEMFs on the growth of the rat mandibular condyle because the secondary cartilage of that condyle resembles the fibrocartilage of bone fractures both functionally and histologically (Bassett, 1982a, b; Gerling et al., 1985). The mandibular condyle is derived from hyaline cartilage that arises in association with periosteum after the emergence of primary hyaline cartilages elsewhere. As a secondary cartilage, the mandibular condyle is able to respond and adapt to external stimuli, unlike primary hyaline cartilages (van Limborg, 1970, 1972; McNamara, 1972; Koski, 1977; Petrovic and Stutzmann, 1977; Carlson et al., 1980; Petrovic, 1982)

Histologically, the condyle is divided into two main layers, an articular layer and a subarticular layer of growth cartilage and bone. The cartilage is covered by a fibrous articular tissue that is contiguous with, and indistinguishable from, the fibrous layer of periosteum covering the rest of the mandible. The articular layer is essentially avascular with a few associated fibroblasts. There are three layers of the subarticular growth cartilage: (1) the proliferative or prechondroblastic layer; (2) the chondroblastic layer, which is subdivided into a zone of maturation and a zone of hypertrophy and (3) the endochondral ossification layer.

As positive findings have been made with PEMF in bone wound healing (Bassett, 1968; Bassett, Mitchell and Gaston, 1981; Bassett, Pawluk and Pilla, 1974), we now wanted to examine the effects of PEMF on growth of the condylar cartilage in the hope of enhancing overall condylar and mandibular growth. The mechanism of action of PEMFs is poorly understood; therefore we wanted to test the two components of the PEMF, magnetic and electrical, for differences in effect. Thus, our study differs from previous studies in that the growing animals were placed within different regions of the PEMF to study the effect of a greater magnetic versus electrical stimuli.

\section{MATERIALS AND METHODS}

\section{Experimental procedures}

Forty-five male pre-adolescent (28-day-old) Sprague-Dawley rats $(80-110 \mathrm{~g})$ were divided into three experimental groups of five animals each. The three groups were: (1) PEMF-M (high magnetic, low electrical field); (2) PEMF-E (high electrical, low magnetic field) and (3) control. In order to ascertain the effects of PEMFs over time, each group was studied after a dose exposure of $8 \mathrm{~h} /$ day for 3,7 or 14 days.

The animals were fed a diet of softened rodent laboratory chow (Purina Mills, Inc.) and water ad libitum. Food was withheld from all groups during the $8 \mathrm{~h}$ of exposure to PEMF. The rats were kept in a $12 \mathrm{~h}$ light-12 $\mathrm{h}$ dark cycle throughout the experiment.

All animals were injected intraperitoneally (i.p.) at the onset of the experiment with $2.0 \mu \mathrm{Ci} / \mathrm{g}$ body weight $\left[{ }^{3} \mathrm{H}\right]$-proline (sp. act. $1 \mathrm{Ci} / \mathrm{mmol}$; New England Nuclear Co., Boston, MA, U.S.A.). One h before killing the animals were injected i.p. on the right-hand side with $\left[{ }^{3} \mathrm{H}\right]$-proline following the above protocol and injected i.p. on the left-hand side with $0.5 \mu \mathrm{Ci} / \mathrm{g}$ body weight $\left[{ }^{3} \mathrm{H}\right]$-thymidine $\left(\left[{ }^{3} \mathrm{H}\right]-\mathrm{TdR}\right.$; sp. act. 6.7 Ci $/ \mathrm{mmol}$; New England Nuclear Co.). This schedule allowed two bands of the hydroxyproline in collagen to be labelled in the cartilage and bone. The $\left[{ }^{3} \mathrm{H}\right]$-thymidine regimen allowed labelling of cells subsequently entering mitosis, thus giving an assessment of cell proliferation.

The animals were then anaesthetized, before decapitation, by intramuscular injection of a mixture of ketamine $(100 \mathrm{mg} / \mathrm{ml})$ and Rompun (xylazine, $100 \mathrm{mg} / \mathrm{ml}$ ) at a dose of $0.5 \mathrm{ml}$ of mixture $/ \mathrm{kg}$ body weight.

\section{PEMF Design}

The PEMF chamber was designed with the coils in a Helmholtz configuration and connected to a signal generator and amplifier. By definition, in a Helmholtz configuration, the mean radius of the coils equals the distance of separation of the coils vertically, and the magnetic and electric fields do not vary in the vertical plane within the partitioned rings. The coils were made of copper wire $1 / 16 \mathrm{in}$. thick with 30 winds of each coil in the horizontal plane. The two coils were separated vertically by a distance of $14.3 \mathrm{~cm}$ with the mean diameter of the coils being $28.6 \mathrm{~cm}$. An electric signal was pulsed through the coils producing a PEMF with a repetitive train of 20 pulses for a total duration of $380 \mu \mathrm{s}$ (positive going) and spaced $55 \mathrm{~ms}$ apart. The wave form was quasirectangular and repeated at a frequency of $72 \mathrm{~Hz}$. The amplitude was adjusted to yield $15 \mathrm{mV}$ on a standardized coil probe, placed midfield, parallel to the coil faces and connected directly to an oscilloscope. This measure was checked daily for calibration using the midfield probe.

The chamber was partitioned into three concentric rings to control the animals' movement in the horizontal plane and thus their exposure to the electrical or magnetic regions of the field (Fig. 1). The animals were not physically restrained other than by being placed within the partitioned inner and outer chambers of the chamber. The animals were free to 


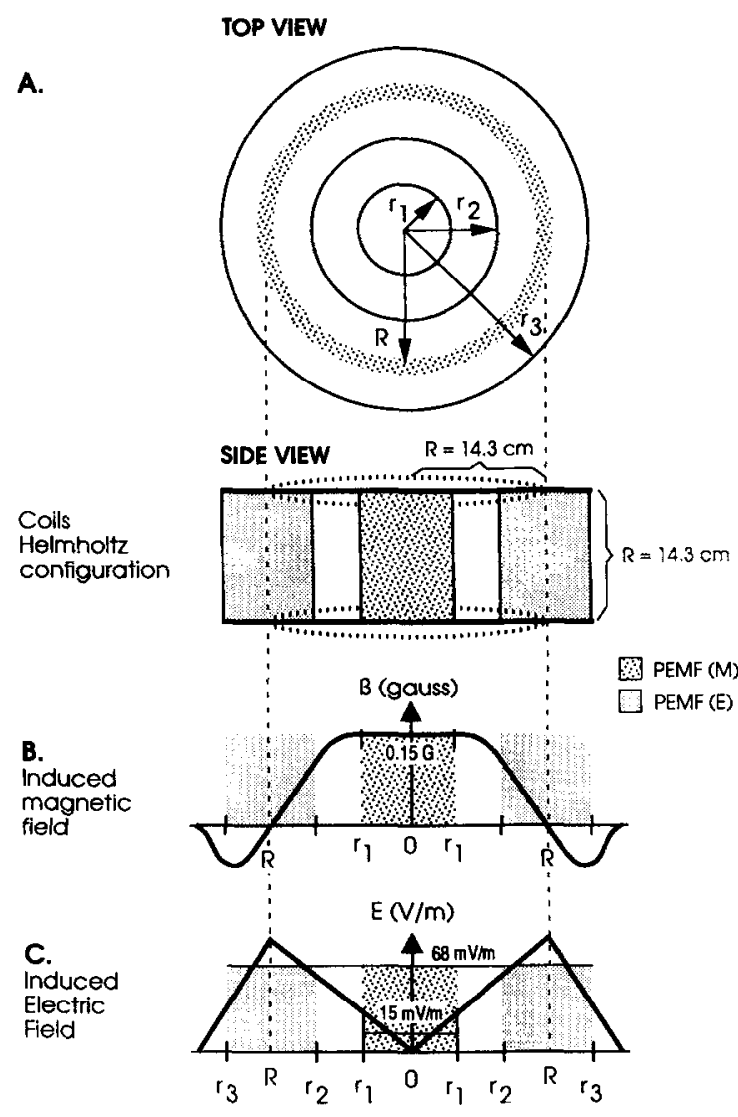

Fig. 1. (A) Top and side views of the PEMF apparatus constructed of concentric lucite cylinders. The apparatus was $R=14.3 \mathrm{~cm}$ tall and had radii of $r_{1}=7.75 \mathrm{~cm}$, $r_{2}=13 \mathrm{~cm}$ and $r_{3}=23 \mathrm{~cm}$. The animals were placed in the inner chamber, PEMF-M, and outer chamber, PEMF-E, for $8 \mathrm{~h} /$ day during the nocturnal phase. The superior and inferior layers of plexiglass had two coils $(28.6 \mathrm{~cm}$ dia) arranged in a Helmholtz configuration. (B) Schematic representation of the induced magnetic field across the horizontal axis of the PEMF apparatus. Animals in the inner cylinder (PEMF-M) had an induced magnetic field of $0.15 \mathrm{G}$ and the outer cylinder (PEMF-E) had a negligible magnetic field exposure calculated using the Biot-Savart law. (C) Schematic representation of the induced electrical field across the horizontal axis of the PEMF apparatus. Animals placed in the inner cylinder (PEMF-M) had an average electric field of $15 \mathrm{mV} / \mathrm{m}$ and those placed in the outer cylinder (PEMF-E) had an induced electric field of $68 \mathrm{mV} / \mathrm{m}$ calculated using Faraday's law.

roam, lie down, and had access to water during the 8-h exposure, identical to the home-cage control group. The exposed and control animals were all maintained on a $12 \mathrm{~h}$ light $-12 \mathrm{~h}$ dark cycle with the PEMF groups being exposed during the night cycle. One group of animals (PEMF-M) was placed in the inner circle and a second group in the outer circle (PEMF-E). The animals were exposed simultaneously in the inner PEMF-M and outer PEMF-E chambers with no shielding. The magnitude within the inner ring for the high magnetic field was calculated to be approx. $0.15 \mathrm{G}$ using the Biot-Savart law, whereas the average magnitude of the induced electrical field on the rat and condylar tissues was calculated to be approx. $15 \mathrm{mV} / \mathrm{m}$ using Faraday's law. The average magnitude within the outer ring for the larger induced electrical field was $68 \mathrm{mV} / \mathrm{m}$ on the rat and condylar tissues while the magnetic field was negligible in this region (Fig. 1).

\section{Histological processing}

After killing, each right hemimandible was removed, placed in phosphate-buffered formalin for 5 days, washed and demineralized in $0.5 \mathrm{~mol} / 1 \mathrm{EDTA}$ (monitored hy X-ray films). The tissue was then dehydrated and paraffin embedded. Specimens were oriented to obtain coronal $5-\mu \mathrm{m}$ sections. Sections were mounted on glass slides, deparaffinized, dipped in NTB-2 nuclear track emulsion (Eastman Kodak Co., Rochester, NY, U.S.A.), and exposed for 14 days at $4^{\circ} \mathrm{C}$. Slides were developed in Kodak D-19 developer and rapid fix, washed, and lightly counterstained with Harris' haematoxylin and eosin.

\section{Autoradiographic and statistical analysis}

Three anterior, posterior and mid-condylar coronal sections were selected from each animal for quantitative analysis on a Zidas Image Analysis System (Carl Zeiss Inc., Thornwood, NY, U.S.A.). Three measurements were taken on each section, selected and averaged to reduce the variability of a single measurement. The optic piece was fitted with a linear ruler and a square grid. The ruler was oriented perpendicular to the condyle at the greatest height of contour to allow a linear measurement of the superior and inferior limits of the following zones of condylar cartilage (Fig. 2): (1) articular zone; (2) zone of proliferation and (3) zones of maturation and hypertrophy.

Quantification of osseous changes was made by measuring the amount of matrix between the parallel proline bands in the neck of the condyle using the method of Tonna (1976) (Fig. 3). The $\left[{ }^{3} \mathrm{H}\right]$-proline bands were not measured in the 14-day animals because it was difficult to visualize the paired bands but all the other measurements were made at this time interval. Cell turnover was measured by positioning the square grid over the greatest height of contour of the condylar proliferative zone and counting the number of $\left[{ }^{3} \mathrm{H}\right]$-thymidine labelled cells within the grid (Fig. 4). A cell was scored as positive if more than three silver grains were present. At the magnification of $400 \times$, the area of the grid was $13.2 \mu \mathrm{m}^{2}$.

The mean, SD and SEM were calculated for each group. Statistical analysis included a two-way ANOVA with the two variables being length of temporal exposure $(3,7$ or 14 days) and type of field (PEMF-M, PEMF-E or none). When a significant interaction was noted between these two variables, a one-way ANOVA was made. Statistical significance was set at the $p \leqslant 0.05$ level.

\section{RESULTS}

The mean and SEM for all measurements can be found in Table 1. Statistical significance for the two variables, time effects and field effects, and the interaction time $\times$ field as determined by a two-way ANOVA can be found in Table 2 . 
Field effects had a statistically significant influence on the thickness of the articular zone in all three regions of the condyle. Due to the morphology of the condylar cartilage cap, which is situated posteriorly and superiorly, the measurements of thickness were largest in the posterior coronal sections and smaller in the anterior coronal sections because the condylar cartilage thins anteriorly. Animals exposed to no field (control) had the highest mean thickness, followed by PEMF-E and PEMF-M (Fig. 5). In the posterior region of the condyle there were statistically significant differences in the thickness of the articular zone over time. The mean average thickness for each time-point in the posterior condyle, regardless of field exposure, was: 7 days, $25.9 \mu \mathrm{m} ; 3$ days, $20.9 \mu \mathrm{m} ; 14$ days, $20.2 \mu \mathrm{m}$. The two-way ANOVA also showed a statistically significant interaction between the time effects and field effects on thickness of the articular zone for the mid- and posterior regions of the condyle. Further analysis with a one-way ANOVA and Scheffe's $F$-test demonstrated that the PEMF-M had the most inhibitory effect in the 7-day group $(p=0.0001)$.

The length of the experiment (3, 7 or 14 days) had a significant association with thickness of the proliferative zone in all three condylar regions (Fig. 6). In the mid-and posterior regions, the greatest thickness was observed in the 7-day groups, and in the anterior

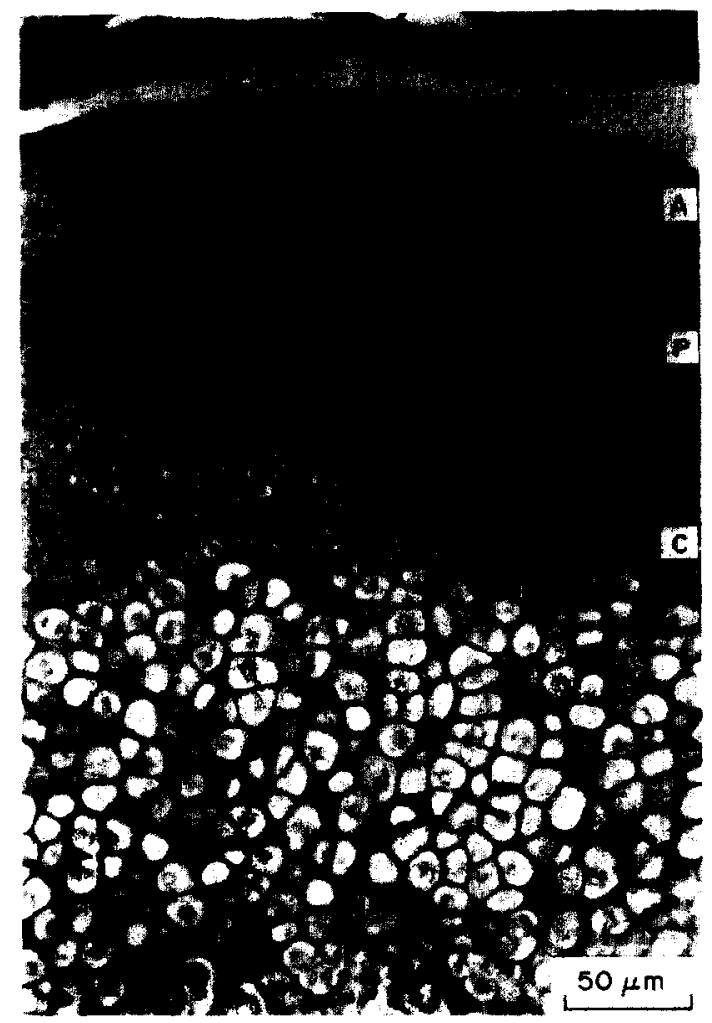

Fig. 2. Histological section through rat mandibular condyle, haematoxylin-eosin stain. The following cartilage zones can be seen: articular zone (A), proliferative zone (P) and the chondroblastic layer $(C)$ containing the zones of maturation and hypertrophy. Within the proliferative zone, silver grains for the nuclear autoradiographic label $\left[{ }^{3} \mathrm{H}\right]$-thymidine can be seen, arrows. $\times 100$ region the greatest thickness was seen in the 3-day groups. For all condylar regions, the 14-day groups had the most reduction in thickness of the proliferative zone.

Reduction in thickness of the maturation and hypertrophic zones of the condylar cartilage over time was also statistically significant in the mid and anterior regions of the condyle (Table 1). The mean average values at each time-point, regardless of field exposure, in the anterior condylar proliferative zone were: 3 days, $344.5 \mu \mathrm{m} ; 7$ days, $266.0 \mu \mathrm{m} ; 14$ days, $222.5 \mu \mathrm{m}$. In the mid-condyle region the values were: 3 days, $422.7 \mu \mathrm{m} ; 7$ days, $318.1 \mu \mathrm{m} ; 14$ days, $310.7 \mu \mathrm{m}$.

The thickness of the proline band shows the amount of bone deposition between the two labelling injections. Thus, as expected, the increase in this measurement with time was statistically significant in all three condylar regions. The mean values for the 3-day group regardless of field exposure were: anterior condyle, $20.8 \mu \mathrm{m}$; mid-condyle, $20.3 \mu \mathrm{m}$; posterior condyle, $18.1 \mu \mathrm{m}$. The mean values for the 7-day group regardless of field exposure were: anterior, $30.1 \mu \mathrm{m}$; mid, $28.3 \mu \mathrm{m}$; posterior, $27.7 \mu \mathrm{m}$. As mentioned above, the thickness of the proline band could not be measured in the 14-day group. There was no association between type of field exposure (PEMF-M, PEMF-E, or none) and the amount of osseous activity.

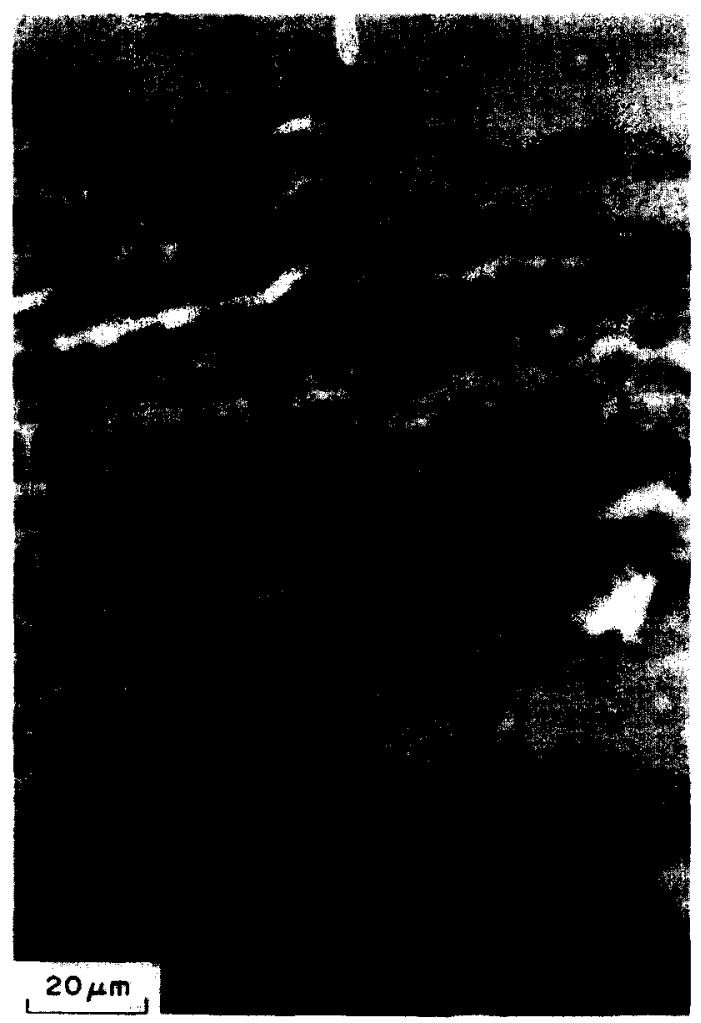

Fig. 3. Double bands of $\left[{ }^{3} \mathrm{H}\right]$-proline (paired arrows) incorporated into new bone matrix in the ossification zone of the mandibular ramus in a control 3-day animal. $\left[{ }^{3} \mathbf{H}\right]$-proline was given at time 0 and $1 \mathrm{~h}$ before killing; haemotoxylin-eosin stain. $\times 250$ 
Table 1. Mean values \pm SEM for condylar measurements: articular zone, proliferative zone, maturation and hypertrophic zone, osseous deposition between paired proline bands, and number of [ $\left.{ }^{3} \mathrm{H}\right]$-thymidine labelled cells

\begin{tabular}{lccccccc}
\hline Region & Time & Field & $\begin{array}{c}\text { Articular } \\
\text { zone }(\mu \mathrm{m})\end{array}$ & $\begin{array}{c}\text { Proliferative } \\
\text { zone }(\mu \mathrm{m})\end{array}$ & $\begin{array}{c}\text { Maturation/ } \\
\text { hypertrophic } \\
\text { zone }(\mu \mathrm{m})\end{array}$ & $\begin{array}{c}\text { Proline } \\
\text { bands }(\mu \mathrm{m})\end{array}$ & $\begin{array}{c}\text { TdR cells } \\
\left(\text { No. } 13.2 \mu \mathrm{m}^{2}\right)\end{array}$ \\
\hline Anterior & 14 & PEMF-M & $16 \pm 1$ & $46 \pm 2$ & $201 \pm 22$ & - & $5.92 \pm 1.07$ \\
& 14 & PEMF-E & $18 \pm 2$ & $52 \pm 3$ & $174 \pm 26$ & - & $6.00 \pm 1.63$ \\
& 14 & None & $17 \pm 3$ & $56 \pm 12$ & $293 \pm 94$ & - & $4.00 \pm 1.04$ \\
& 7 & PEMF-M & $14 \pm 1$ & $43 \pm 4$ & $175 \pm 14$ & $31 \pm 2$ & $1.50 \pm 0.29$ \\
& 7 & PEMF-E & $16 \pm 1$ & $68 \pm 4$ & $281 \pm 16$ & $32 \pm 2$ & $4.33 \pm 0.38$ \\
& 7 & None & $22 \pm 1$ & $88 \pm 15$ & $326 \pm 8$ & $28 \pm 1$ & $4.67 \pm 0.33$ \\
& 3 & PEMF-M & $17 \pm 1$ & $74 \pm 14$ & $371 \pm 50$ & $20 \pm 2$ & $3.53 \pm 1.06$ \\
& 3 & PEMF-E & $21 \pm 2$ & $100 \pm 14$ & $332 \pm 37$ & $22 \pm 1$ & $4.73 \pm 0.82$ \\
Mid & 3 & None & $20 \pm 2$ & $92 \pm 25$ & $331 \pm 34$ & $20 \pm 1$ & $2.73 \pm 0.75$ \\
& 14 & PEMF-M & $19 \pm 2$ & $65 \pm 8$ & $347 \pm 22$ & - & $5.83 \pm 0.67$ \\
& 14 & PEMF-E & $17 \pm 1$ & $72 \pm 6$ & $242 \pm 20$ & - & $7.25 \pm 1.25$ \\
& 14 & None & $19 \pm 3$ & $68+14$ & $243 \pm 29$ & -1.29 & $5.17 \pm 1.83$ \\
& 7 & PEMF-M & $15 \pm 1$ & $98 \pm 39$ & $225 \pm 19$ & $29 \pm 2$ & $2.42 \pm 0.37$ \\
& 7 & PEMF-E & $21 \pm 1$ & $131 \pm 24$ & $318 \pm 40$ & $29 \pm 1$ & $5.00 \pm 0.77$ \\
& 7 & None & $25 \pm 1$ & $126 \pm 10$ & $392 \pm 43$ & $27 \pm 1$ & $6.40 \pm 0.44$ \\
& 3 & PEMF-M & $20 \pm 1$ & $74 \pm 16$ & $491 \pm 81$ & $22 \pm 2$ & $5.70 \pm 1.87$ \\
& 3 & PEMF-E & $21 \pm 1$ & $132 \pm 38$ & $396 \pm 69$ & $21 \pm 2$ & $4.27 \pm 0.85$ \\
& 3 & None & $22 \pm 1$ & $90 \pm 24$ & $381 \pm 46$ & $17 \pm 1$ & $3.13 \pm 1.16$ \\
& 14 & PEMF-M & $19 \pm 2$ & $103 \pm 10$ & $464 \pm 24$ & - & $8.58 \pm 1.4$ \\
& 14 & PEMF-E & $17 \pm 2$ & $88 \pm 9$ & $302 \pm 28$ & - & $8.33 \pm 0.78$ \\
& 14 & None & $24 \pm 4$ & $93 \pm 19$ & $531 \pm 43$ & - & $7.33 \pm 2.09$ \\
& 7 & PEMF-M & $17 \pm 2$ & $108 \pm 35$ & $318 \pm 68$ & $26 \pm 2$ & $2.83 \pm 1.51$ \\
& 7 & PEMF-E & $25 \pm 1$ & $165 \pm 16$ & $368 \pm 36$ & $30 \pm 2$ & $6.73 \pm 1.19$ \\
& 7 & None & $34 \pm 3$ & $146 \pm 8$ & $437 \pm 53$ & $27 \pm 1$ & $8.00 \pm 0.84$ \\
& 3 & PEMF-M & $19 \pm 2$ & $113 \pm 21$ & $494 \pm 100$ & $18 \pm 2$ & $3.67 \pm 1.25$ \\
& 3 & PEMF-E & $22 \pm 3$ & $142 \pm 28$ & $401 \pm 65$ & $19 \pm 1$ & $6.07 \pm 1.07$ \\
& 3 & None & $22 \pm 1$ & $140 \pm 29$ & $375 \pm 79$ & $18 \pm 1$ & $4.75 \pm 0.69$ \\
\hline
\end{tabular}

There was a statistically significant increase in $\left[{ }^{3} \mathrm{H}\right]-\mathrm{TdR}$ labelling in the anterior and posterior regions of the condyle in relation to the length of the experiment. The 14-day groups had the highest number of labelled cells. In the anterior condyle, the mean values were: 14 day, 5.2 cells; 3 day, 3.7 cells; 7 day, 3.6 cells. In the posterior condyle, the mean values were: 14 day, 5.2 cells; 3 day, 3.7 cells; 7 day,
3.6 cells. In the posterior condyle, the mean values were: 14 day, 8.1 cells; 7 day, 5.9 cells; 3 day, 4.8 cells.

\section{DISCUSSION}

We have quantitatively studied the effects of PEMFs on the growth of the rat mandibular condyle

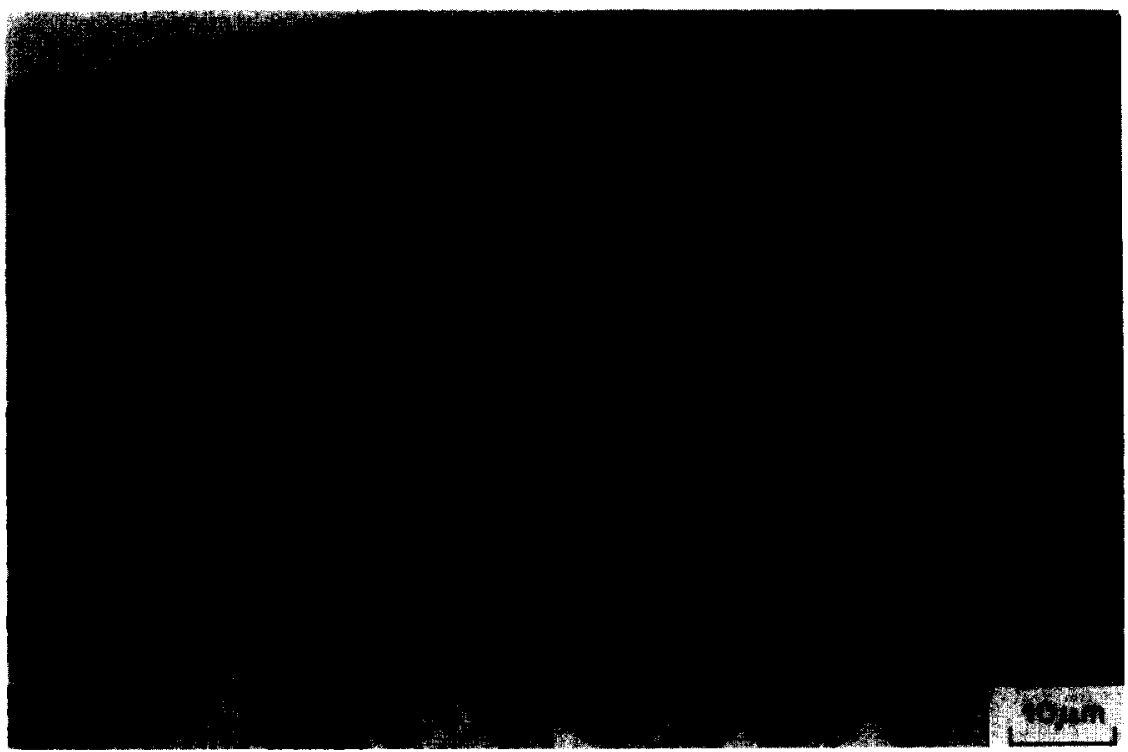

Fig. 4. Dual labelling in the proliferative zone of the rat mandibular condyle with $\left.{ }^{3} \mathrm{H}\right]$-thymidine for the nuclei (arrows) and with $\left[{ }^{3} \mathrm{H}\right]$-proline for the cartilage matrix in a 14-day PEMF-E animal. The labels were given i.p. $1 \mathrm{~h}$ before killing; haemotoxylin-eosin stain. $\times 400$ 
Table 2. Statistical significance, $p$ values, for the two variables time and field and the interaction time $\times$ field determined by a two-way ANOVA

\begin{tabular}{|c|c|c|c|c|c|c|}
\hline Region & Variables & $\begin{array}{l}\text { Articular } \\
\text { zone }\end{array}$ & $\begin{array}{l}\text { Proliferative } \\
\text { zone }\end{array}$ & $\begin{array}{l}\text { Maturation/ } \\
\text { hypertrophic }\end{array}$ & $\begin{array}{l}\text { Proline } \\
\text { bands }\end{array}$ & $\begin{array}{l}\text { TdR } \\
\text { Cells }\end{array}$ \\
\hline \multirow[t]{3}{*}{ Anterior } & Time & NS & 0.008 & 0.002 & 0.0001 & 0.05 \\
\hline & Field & 0.02 & NS & NS & NS & NS \\
\hline & $\mathrm{T} \times \mathrm{F}$ & NS & NS & NS & NS & NS \\
\hline \multirow[t]{3}{*}{ Mid } & Time & NS & 0.05 & 0.01 & 0.0001 & NS \\
\hline & Field & 0.001 & NS & NS & NS & NS \\
\hline & $\mathrm{T} \times \mathrm{F}$ & 0.01 & NS & NS & NS & 0.05 \\
\hline \multirow{3}{*}{ Posterior } & Time & 0.03 & 0.007 & NS & $0.000 \mathrm{l}$ & 0.01 \\
\hline & Field & 0.0006 & NS & NS & NS & NS \\
\hline & $\mathrm{T} \times \mathrm{F}$ & 0.05 & NS & NS & NS & NS \\
\hline
\end{tabular}

The time variable (length of experiment) was signiticant for most of the measures, whereas the field exposure variable (PEMF-M, PEMF-E or none) had an effect only on the thickness of the articular zone.

by autoradiography, differentiating between the effects of the magnetic and the electrical components of the field. The effects were analysed at 3,7 and 14 days, corresponding with active adolescent and maturing growth. At these three times, the killed rats were thus 31,35 or 42 days old.

One variable, the field effects, only affected the thickness of the articular zone, with the PEMF-M group showing the most reduction in thickness in all three regions of the condyle examined. This finding in part supports those of Fitton-Jackson and Bassett (1980), who found that larger magnetic fields had a negative chondrogenic and a positive osteogenic effect. We found a chondrogenic effect on the articular layer of the condyle, but no other differences in chondrogenic or osteogenic measurements were noted.

The presence of electric fields is known to have a positive effect on bone healing and to affect tooth movement. Electric fields can be induced either by invasively placed electrodes (Fukada and Yasuda, 1957; Bassett, 1968, 1971; Davidovitch et al., $1980 \mathrm{a}-\mathrm{c}$ ) or by non-invasive PEMFs (Brighton et al., 1975; Bassett et al., 1974a, b, 1981; Bassett, Pilla and Pawluk, 1977; Sedel et al., 1982; Hinsenkamp, 1982). The main application of PEMFs has been in healing

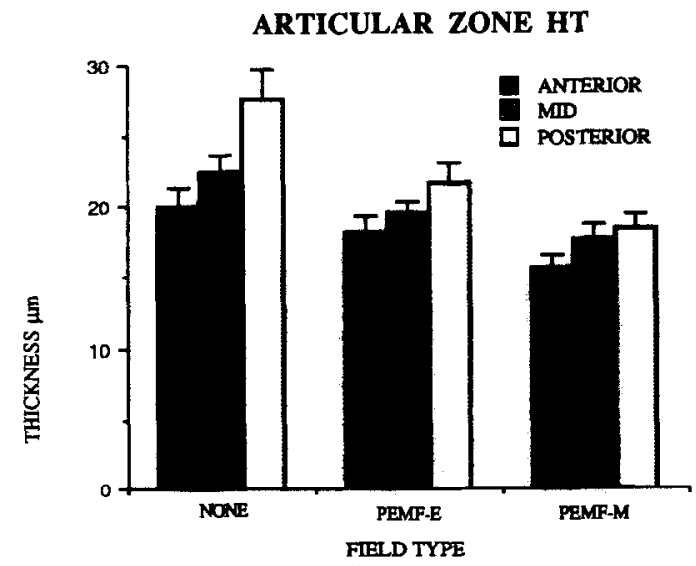

Fig. 5. The effect of field (PEMF-E, PEMF-M and none) on height of the articular zone was statistically significant across all time intervals ( 3,7 and 14 days) by two-way ANOVA. Mean values \pm SEM. The $p$ values were: anterior condyle $p=0.02$, mid-condyle $p=0.001$, posterior condyle $p=0.0006$. of non-union bone fractures, and it has been supposed that the electrical component of the field is responsible for the changes observed.

As expected, the length of time that the animal was in the experiment had predictable significance in relation to most of the measurements of thickness for the condylar zones and proline bands. The proline bands were the thickest in the older animals as bone was deposited, and, as the animals aged, less growth of condylar cartilage occurred, resulting in a decrease in the height of the condylar zones. This slowing of growth occurred between 35 and 42 days of age, as the 7-day animals had the greatest height for many of the condylar zones measured. This pattern corresponds with the maturation of the rat and the slowing of growth between 35 and 42 days of age. A timecourse experiment could determine exactly when this decrease begins. Morphologically, the growth cartilage is thickest on the posterior and superior surfaces: thus in the coronal sections the mean of our measurements generally increased from the anterior to the posterior regions (Carlson, McNamara and Jaul, 1978).

Petrovic and Stutzmann (1977) and Petrovic, Stutzmann and Oudet (1975) have also noted similar time-dependent changes in the thickness of the

\section{PROLIFERATIVE ZONE HT}

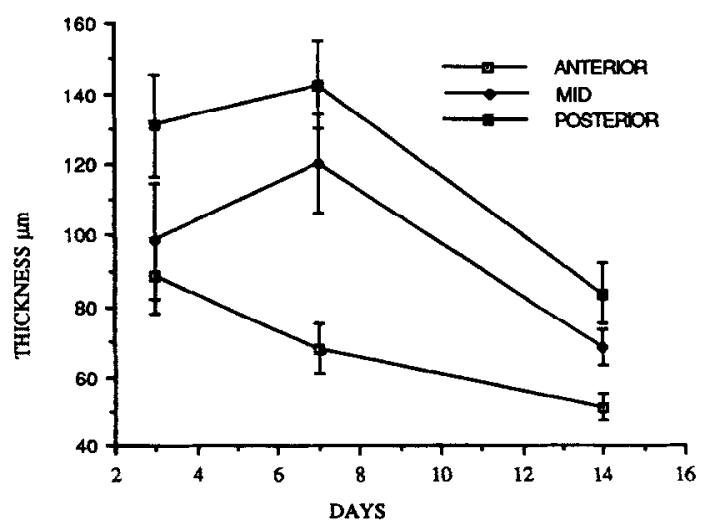

Fig. 6. The effect of length of experiment on proliferative zone height was statistically significant regardless of the field by two-way ANOVA. Mean values \pm SEM for each time point. The $p$ values were: anterior condyle $p=0.008$, midcondyle $p=0.05$, posterior condyle $p=0.007$. 
condylar cartilage zones in rats, and Carlson et al. (1978) found these time-dependent changes in monkeys. Gerling et al. (1985) looked at guinea-pig mandibles exposed to PEMFs at 10 and 30 days and obtained results similar to ours: i.e. an increase in the secretion of cartilage matrix and the formation of woven bone in 10-day animals but at 30 days the increases first seen were diminished. Gerling's study was non-quantitative (except for osteoclasts) and qualitatively described the histological changes. Other differences between the Gerling study and our study were that (1) the animals were of a different species, yet both were growing, and (2) the PEMF field was different, i.e. $100 \mathrm{~Hz}$ frequency versus 72 $\mathrm{Hz}$. It is difficult to extrapolate between these two sets of findings, but the trends are similar: a decrease in cellular activity and a decrease in growth in the condylar zones over time as the animals mature.

We also found a statistically significant difference in $\left[{ }^{3} \mathrm{H}\right]-\mathrm{TdR}$ labelling for the anterior and posterior regions of the condyle over the length of the experiment (3, 7 or 14 days). Here, unlike condylar thickness, which had greatest mean value at 7 days, the greatest number of labelled cells was seen at 14 days, when active growth was decreasing. The 14-day groups were of mature male rats 42 days old. The number of dividing cells therefore appeared to increase as the thickness of the proliferative zone decreased. This paradoxical finding, which requires further investigation, may imply that there are more cells per area, thus more cells undergoing division, as the amount of extracellular matrix decreases and growth slows.

The significant interactions between field effects and time effects on thickness of the articular zone for the mid-and posterior regions of the condyle showed that PEMF-M had the greatest inhibitory effect in the 7-day group. This can be explained by the greatest thickness being at 7 days, as discussed above. Inhibitory effects and thickness were the two areas that had large singular effects for both variables, time and field, and the finding of a significant interaction is not surprising.

Thus, by varying the electrical and magnetic components of the PEMF, an effect was observed on the chondrogenic articular layer of the mandibular condyle, with the PEMF-M being inhibitory. This statistically significant effect probably diminishes once the perturbation stops, and the response returns to that of the normative unperturbed state. Possibly by altering the intensity of the PEMF-E or the length of exposure to the field, a positive effect may be elicited for the chondrogenic tissues as others have suggested (Fitton-Jackson and Bassett, 1980). Also, by altering the characteristics of the PEMF (waveform, frequency and amplitude) different cells may be affected and the attenuation of cellular responses may be maintained. This could be a clinically important finding in that overall changes in size may then be observed.

Acknowledgements-This research was supported by U.S.P.H.S. Research Grants DE 08209 and DE 03610 from the National Institute of Dental Research and the LeGro fund from the University of Michigan.

\section{REFERENCES}

Aaron R. K., Ciombor D. M. and Jolly G. Stimulation of experimental endochondral ossification by low-energy pulsing electromagnetic fields. J. Bone Miner. Res. 4, 227-233.

Bassett C. A. L. (1968) Review: biological significance of piezoelectricity. Calc. Tiss. Res. 1, 252-272.

Bassett C. A. L. (1971) Biophysical principles affecting bone structure. In Biochemistry and Physiology of Bone (Ed. Bourne G. H.), Vol. 3, pp. 1-68. Academic Press, New York.

Bassett C. A. L. (1982a) Pulsing electromagnetic field treatment in ununited fractures and failed arthrodeses. JAMA 247, 623 .

Bassett C. A. L. (1982b) Pulsing electromagnetic fields: a new method to modify cell behavior in calcified and noncalcified tissues. Calc. Tiss. Int. 34, 1-8.

Bassett C. A. L. (1989) Fundamental and practical aspects of therapeutic uses of pulsed electromagnetic fields (PEMFs). Crit. Rev. Biomed. Eng. 17, 451-529.

Bassett C. A. L., Pawluk R. J. and Pilla A. A. (1974a) Acceleration of fracture repair by electromagnetic fields: a surgically noninvasive method. Ann. N.Y. Acad Sci. 238, 242.

Bassett C. A. L., Pawluk R. J. and Pilla A. A. (1974b) Augmentation of bone repair by inductively coupled electromagnetic fields. Science 184, 575-577.

Bassett C. A. L., Pilla A. A. and Pawluk R. J. (1977) A non-operative salvage of surgically resistant pseudoarthroses and nonunions by pulsing electromagnetic fields. Clin. Orthop. 124, 128-143.

Bassett C. A. L., Mitchell S. N. and Gaston S. R. (1981) Treatment of ununited tibial diaphyseal fractures with pulsing electromagnetic fields. J. Bone Jt Surg. 63A, 511-523.

Bawin S. M., Adey W. R. and Sabbot T. M. (1978) Ionic factors in release of ${ }^{45} \mathrm{Ca}^{++}$from chicken cerebral tissue by electromagnetic field. Proc. natn. Acad. Sci., U.S.A. 75, 6314.

Brighton C. I., Friedenberg Z. B., Zemsky L. M. and Pollis B. P. (1975) Direct current stimulation of nonunion and congenital pseudoarthroses. Exploration of its clinical applications. J. Bone Jt Surg. 57A, 368.

Brighton C. T., Friedenberg Z. B., Black J., Pollack S. R., Heppenstall R. B. and Esterhai J. L. (1986) Direct current versus capacitive coupling in treating non unions Trans. BRAGS 6, 84

Carlson D. S., McNamara J. A. and Jaul D. H. (1978) Histological analysis of the growth of the mandibular condyle in the rhesus monkey (Macaca mulatta). Am. $J$. Anat. 151, 103-118.

Carlson D. S., McNamara J. A., Graber L. W. and Hoffman D. L. (1980) Experimental studies of growth and adaptation of the TMJ. In Current Advances in Oral Surgery (Ed. Irby W. B.), Vol. III. Mosby, St Louis, MO.

Davidovitch Z., Finkelson M. D., Steigman S., Shanfield J. L., Montgomery P. C. and Korostoff E. (1980a) Electrical currents, bone remodelling and orthodontic tooth movement I. the effects of electric currents on periodontal cyclic nucleotides. Am. J. Orthod. 77, $14-32$.

Davidovitch Z., Finkelson M. D., Steigman S., Shanfield J. L., Montgomery P. C. and Korostoff E. (1980b) Electric currents, bone remodelling and orthodontic tooth movement I. the effects of electric currents on periodontal cyclic nucleotides. Am. J. Orthod. 77, 14-32.

Davidovitch Z., Finkelson M. D., Steigman S., Shanfield J. L., Montgomery P. C. and Korostoff E. (1980b) Electric currents, bone remodelling and orthodontic tooth movement II. increase in rate of tooth movement and periodontal cyclic nucleotide levels by combined force and electric current. Am. J. Orthod. 77, 33-47. 
Davidovitch Z., Steigman S., Finkelson M. D., Yost R. W., Montogomery P. C., Shanfeld J. L. and Korostoff E, (1980c) Immunohistochemical evidence that electric currents increase periosteal cell cyclic nucleotide levels in feline alveolar bone in vivo. Archs oral Biol. 25, 321.

Fitton-Jackson S. and Bassett C. A. L. (1980) The response of skeletal tissues to pulsed magnetic fields. In Tissue Culture in Medical Research (II) (Eds Richards R. J. and Rajara K. T.). Pergamon Press, Oxford.

Fukada E. and Yasuda I. (1957) On the piezoelectric effect of bone. J. Phys. Soc. Jap. 12, 1158-1162.

Gerling J. A., Sinclain P. M. and Rua R. L. (1985) The effect of PEMF on condylar growth in guinea pig. $A m . J$. Orthod. 87, 211-223.

Goodman R. and Henderson A. S. (1988) Exposure of salivary gland cells to low-frequency electromagnetic fields alters polypeptide synthesis. Proc. natn. Acad. Sci., U.S.A. 85, 3928-3932.

Grodzinsky A. (1983) Electromechanical and physiochemical properties of connective tissue. Crit. Rev. Biomed. Engng 9, 133.

Gupta T. D. Jain V. K. and Tandon P. N. (1991) Comparative study of bone growth by pulsed electromagnetic fields. Med. Biol. Engng. Comput. 29, 113-120.

Hinsenkamp M. G. (1982) Treatment of non-unions by electromagnetic stimulation. Acta Orthop. Scand. 53, 63-79.

lannacone W. M., Pienkowski D., Pollack S. R. and Brighton C. T. (1988) Pulsing electromagnetic field stimulation of the in vitro growth plate. J. Orthop. Res. 6, 239-247.

Jones D. B., Pedley R. B. and Ryaby J. T. (1986) PEMF effects on differentiation and division in murine melanoma cells are mediated indirectly cAMP. Trans. BRAGS 6, 51 .

Kopman C. R., Boskey A. L., Lane J. M., Pita J. C. and Eaton B. (1987) Biochemical characterization of fracture callus proteoglycans. J. Orthop. Res. 5. 7.

Koski K. (1977) The role of the craniofacial cartilages in the postnatal growth of the craniofacial skeleton. In Orofacial Growth and Development (Eds Dalberg A. A. and Graber T. M.), pp. 9-34. Aldine, Chicago, IL.

van Limborg J. (1970) A new view on the control of the morphogenesis of the skull. Acta Morph. Neerl-Scand. 8 , 143-160.

van Limborg J. (1972) A new view on the control of the morphogenesis of the skull. Acta Morph. Neerl-Scand. 10, $37-47$.

McNamara J. A. (1972) Neuromuscular and Skeletal Adaptations to Altered Orofacial Function. Monograph 1. Craniofacial Growth Series. Center for Human Growth and Development, The University of Michigan, Ann Arbor, MI
Noda M. and Sato A. (1985) Calcification of cartilagenous matrix in culture by constant direct current stimulation. Clin. Orthop. Relat. Res. 193, 281.

Norton L. A. (1982) Effects of a pulsed electromagnetic field on mixed chondroblastic tissue culture. Clin. Orthop Relat. Res. 167, 280.

Norton L. A. (1985) Pulsed electromagnetic field effects in chondroblast culture. Reconstr. Surg. Traumat. 19, 70.

Norton L. A., Rodan G. A. and Bourret L. A. (1977) Epiphyseal cartilage cAMP changes produced by electrical and mechanical perturbations. Clin. Orthop. Relat. Res. 124, 59

Nuiton L. A., Hanley K. J. and Turkewicz J. (1984) Bioelectric perturbations of bone-research directions and implications. Angle Orthod. 54, 73.

Norton L. A., Witt D. W. and Rovetti L. A. (1988) Pulsed electromagnetic fields alter phenotypic expression in chondroblasts in tissues culture. J. Orthop. Res. 6, 685-689.

Petrovic A. G. (1982) Altering craniofacial growth: evidence from experimental studies. In Clinical Alteration of the Growing Face: the Michigan Symposium Through the Eyes of the Editor, Part I and II (Ed. Watson W. G.). Am. J. Orthod. 82, 343-346, $430-433$.

Petrovic A. G. and Stutzmann J. J. (1977) Further investigation into the functioning of the "comparator" of the servosystem in the control of the condylar cartilage growth rate and the lengthening of the jaw. In The Biology of Occlusal Development, (Ed. McNamara J. A.). Monograph 7, Craniofacial Growth Series, pp. 252-292. Center for Human Growth and Development, The University of Michigan, Ann Arbor, MI 1977, 255-292.

Petrovic A. G., Stutzmann J. J. and Oudet C. (1975) Control process in the postnatal growth of the condylar cartilage. In Determinants of Mandibular Form and Growth, (Ed. MeNamara J. A.), Monograph 4, Craniofacial Growth Series, pp. 101-154. Center for Human Growth and Development, The University of Michigan, Ann Arbor, MI

Rodan G. A., Bourret L. A. and Norton L. A. (1978) DNA synthesis in cartilage cells is stimulated by oscillating electric fields. Science 199, 690-692.

Ryaby J. T., Jones D. B. and Pilla A. A. (1986) The effects of electromagnetic fields on protein phosphorylation and synthesis in murine melanoma cells. Trans. BRAGS 6, 33.

Sedel L., Christel P., Duriez J., Duriez R., Evrard J., Ficat C., Cauchoix J. and Witvoet J. (1982) Results of nonunions treatment by pulsed electromagnetic field stimulation. Acta. Orthop. Scand. 53, $81-91$

Stark T. M. and Sinclair P. M. (1987) Effects of pulsed electromagnetic fields on orthodontic tooth movement. Am. J. Orthod. 91, 91

Tonna E. A. (1976) Topographic labelling method using ${ }^{3} \mathrm{H}$-proline autoradiography in assessment of aging parodontal bone in the mouse. Archs oral Biol. 21, 729-740. 